\title{
Effect of sulfate on the transformation of corrosion scale composition and bacterial community in cast iron water distribution pipes
}

\author{
Fan Yang ${ }^{a, b}$, Baoyou Shi ${ }^{a, *}$, Yaohui Bai ${ }^{a}$, Huifang Sun ${ }^{a}$, Darren A. Lytle ${ }^{c}$, \\ Dongsheng Wang ${ }^{a}$ \\ a State Key Laboratory of Environmental Aquatic Chemistry, Research Center for Eco-Environmental Sciences, \\ Chinese Academy of Sciences, Beijing 100085, China \\ ${ }^{\mathrm{b}}$ College of Engineering and Technology, Tianjin Agricultural University, Tianjin 300384, China \\ ${ }^{\mathrm{c}}$ United States Environmental Protection Agency, 26 W. Martin Luther King Dr, Cincinnati, OH 45268, USA
}

\section{A R T I C L E I N F O}

\section{Article history:}

Received 28 October 2013

Received in revised form

27 March 2014

Accepted 2 April 2014

Available online 13 April 2014

\section{Keywords:}

Drinking water distribution system

(DWDS)

Corrosion scale

Iron release

Bacterial community

Sulfate

\begin{abstract}
A B S T R A C T
The chemical stability of iron corrosion scales and the microbial community of biofilm in drinking water distribution system (DWDS) can have great impact on the iron corrosion and corrosion product release, which may result in "red water" issues, particularly under the situation of source water switch. In this work, experimental pipe loops were set up to investigate the effect of sulfate on the dynamical transformation characteristics of iron corrosion products and bacterial community in old cast iron distribution pipes. All the test pipes were excavated from existing DWDS with different source water supply histories, and the test water sulfate concentration was in the range of 50-350 mg/L. Pyrosequencing of $16 \mathrm{~S}$ rRNA was used for bacterial community analysis. The results showed that iron release increased markedly and even "red water" occurred for pipes with groundwater supply history when feed water sulfate elevated abruptly. However, the iron release of pipes with only surface water supply history changed slightly without noticeable color even the feed water sulfate increased multiply. The thick-layered corrosion scales (or densely distributed tubercles) on pipes with surface water supply history possessed much higher stability due to the larger proportion of stable constituents (mainly $\mathrm{Fe}_{3} \mathrm{O}_{4}$ ) in their top shell layer; instead, the rather thin and uniform non-layered corrosion scales on pipes with groundwater supply history contained relatively higher proportion of less stable iron oxides (e.g. $\beta-\mathrm{FeOOH}, \mathrm{FeCO}_{3}$ and green rust). The less stable corrosion scales tended to be more stable with sulfate increase, which was evidenced by the gradually decreased iron release and the increased stable iron oxides. Bacterial community analysis indicated that when switching to high sulfate water, iron reducing bacteria (IRB) maintained dominant for pipes with stable corrosion scales, while significant increase of sulfur oxidizing bacteria (SOB), sulfate reducing bacteria (SRB) and iron oxidizing bacteria (IOB) was observed for pipes with less stable corrosion scales.
\end{abstract}

(c) 2014 Elsevier Ltd. All rights reserved.

\footnotetext{
* Corresponding author. Tel.: +8610 62849138; fax: +861062923541.

E-mail addresses: byshi@rcees.ac.cn, shibaoyou@yahoo.com (B. Shi).
} 


\section{Introduction}

Switching to alternative source water (e.g. desalinated water, reclaimed water) and long distance water transfer are becoming a trend for solving water shortage problems in the world. Source water switch could cause undesirable water quality changes at consumers' tap resulted from destabilization of corrosion scales and biofilms in existing drinking water distribution systems (DWDS). Disturbance of corrosion scales caused by sudden water chemistry variation can result in discolored, odorous and bad taste water which often leads to consumer complaints and potentially threatens human health (Imran et al., 2006). The effects of source water switch on the deterioration of water quality within DWDS are complicated, and the mechanisms involved are currently unclear.

"Red water" issue had occurred in a northern China city when a new water source was imported from a neighboring province during the recent years. It was interesting to find that red water occurred only in areas historically supplying local groundwater, and the areas without red water were historically supplied with local surface waters. The new water source had significantly higher sulfate compared with the local groundwater (about 200 vs. $30 \mathrm{mg} / \mathrm{L}$ ). Sulfate was deemed to affect the iron pipe corrosion and even lead to red water in many cases (Li et al., 2010), but the involved pathway has not been well understood. Some researchers hold the hypothesis that sulfate within iron corrosion tubercles increase the acidity inside the tubercles, thereby promoting corrosion of the metal and dissolution of the corrosion products. Previous work indicated that the corrosion scales in the DWDS had different morphological and structural characteristics depending on their history of transported source water types; it was suggested that corrosion scales with hard shell layer and high proportion of $\mathrm{Fe}_{3} \mathrm{O}_{4}$ might possess good adaptability to high sulfate water (Yang et al., 2012). As to the roles of microorganisms on red water occurrence, it was proposed that high level of Gallionella spp. as well as other iron-oxidizing bacteria (IOB) in the bulk water could facilitate the precipitation of iron oxides by converting ferrous to ferric iron, thus contributing to the formation of red water (Li et al., 2010). Additionally, sulfate reducing bacteria (SRB) have long been considered to be associated with the promotion of iron corrosion, and hindering the formation of the stable iron oxide - $\mathrm{Fe}_{3} \mathrm{O}_{4}$ (Lytle et al., 2005; Pineau et al., 2008).

The physicochemical properties of corrosion scale could be affected by some water quality parameters, such as $\mathrm{pH}$, oxidation-reduction potential, aqueous ions, microorganisms, and the water flow condition (Sarin et al., 2001, 2004). Biofilm bacterial community in DWDS can also be influenced by chlorine level, concentration of organic compounds, water temperature, and compositional characteristics of pipe materials (Niquette et al., 2001). The metabolic activity of bacteria in corrosion scale has been reported to play important roles in the biogeochemical redox cycling of iron oxides (Iwona and Christine, 1999; Lytle et al., 2005; Erbs, 2004). Therefore, in order to further understand the mechanisms of red water occurrence, it is necessary to elucidate the interactions among main water quality parameters, biofilm bacterial communities and corrosion scale properties.
In recent years, molecular biological methods, including clone library (White et al., 2011), T-RFLP (Pavissich et al., 2010), PCR-DGGE (Teng et al., 2008), particularly pyrosequencing as a more powerful technique (Park et al., 2011) were used to investigate the temporal and spatial distribution of bacterial populations of biofilm on/in corrosion scales. The change of iron corrosion products in DWDS under source water switch had been observed by some researchers (Tang et al., 2006), but the transformation of bacterial community existed in corrosion scale and the chemical composition of corrosion scales under the influence of sulfate concentration has not been reported.

In order to understand the mechanism of iron corrosion byproducts release (iron release) under source water switch and develop possible red water control strategies, in this work, iron pipe sections from actual DWDS with different source water supply histories were collected for pipe loop investigation. The main objective was to elucidate the effect of feed water sulfate variation on the iron release behavior in cast iron distribution pipes, and an emphasis was placed on the stability transformation characteristics of corrosion scale and bacterial community under high sulfate source water switch. Tap water and simulated test water were supplied to pipe loop facilities assembled with pipe sections of different origins. Some main water quality parameters were monitored during each experimental operation phase. The relationships of bacterial community, scale chemical constituents, water quality parameters and total iron release under changing sulfate water condition were analyzed and discussed.

\section{Materials and methods}

\subsection{Test pipes and pipe loop setup}

The test cast iron pipes were all approximately 20 years old, with diameter of DN100 and harvested from three different sites in the DWDS of a city in northern China. The morphological and structural characteristics of the corrosion products on these pipes had been investigated previously (Yang et al., 2012). For consistency of the two works, the three test pipes used in this work were identified using the same symbols as previously, that is, Pipe-SW2, PipeF-SW1/GW1 and PipeCGW3, respectively. Pipe-SW2 was historically transporting a local surface water (denoted as SW2), PipeC-GW3 was transporting a local groundwater (denoted as GW3), and the PipeFSW1/GW1 was supplied by a groundwater and surface water alternately (denoted as SW1/GW1), since they were excavated from the intersection zone of surface water treatment plant 1 (SWTP1) and groundwater treatment plant 1 (GWTP1) service areas.

For the convenience of transportation and installation, each test pipe was cut into $1 \mathrm{~m}$-length experimental pipe sections and $0.1 \mathrm{~m}$-length pipe coupon sections. Fig. 1 shows the assembly of pipe loops used in this study. Two pipe loop facilities were set up in parallel. Each pipe loop facility consisted of five $1 \mathrm{~m}$-length cast-iron pipe sections and three $0.1 \mathrm{~m}$-length pipe coupon sections. The $0.1 \mathrm{~m}$-length pipe coupon was used for corrosion scale observation. 


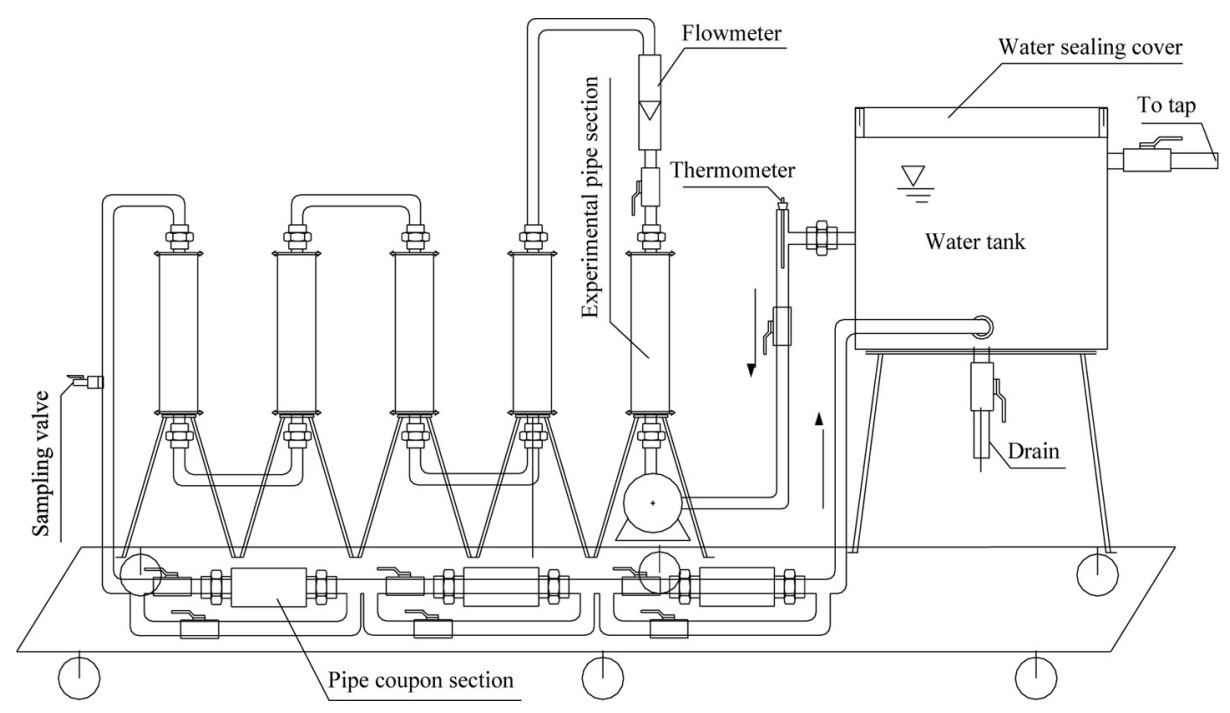

Fig. 1 - Sketch of experimental pipe loop setup.

Pipe-SW2 sections were firstly investigated by connecting them onto two loop facilities, designated as Loop 1 (L1) and Loop 2 (L2), respectively. After finishing the study for PipeSW2, the PipeF-SW1/GW1 and PipeC-GW3 were assembled to the two loop facilities, respectively to replace Pipe-SW2. The loops with PipeF-SW1/GW1 and PipeC-GW3 were designated as Loop 3 (L3) and Loop 4 (L4), respectively.

\subsection{Pipe loop operation}

Experimental operation for each pipe loop was divided into five consecutive phases. Due to the different harvesting time and the distinct corrosion scale characteristics of test pipes, the operation condition and phase definition for the four pipe loops were not exactly the same. Experimental phase definition, detailed operation condition and corresponding feed water types for each pipe loop are presented in Table 1 and Table S1-S4 (in Supporting Information). Simulated test water was prepared by adding sodium sulfate to tap water. Magnesium and chloride concentrations were also adjusted using magnesium sulfate and calcium chloride according to the actual source water characteristics. Some main water quality parameters of both tap water and simulated water during different experimental phases are provided in Table 2. Water samples from the pipe harvesting sites in actual DWDS were also collected and analyzed. Since Larson ratio (LR) is often used as an index to evaluate the corrosiveness of drinking water, and its value is directly correlated with sulfate concentration, LR of simulated water was also calculated (Eq. (1)) and discussed in this study.

$\mathrm{LR}=\frac{\left[\mathrm{Cl}^{-}\right]+2\left[\mathrm{SO}_{4}{ }^{2-}\right]}{\left[\mathrm{HCO}_{3}{ }^{-}\right]}$

where, $\left[\mathrm{Cl}^{-}\right],\left[\mathrm{SO}_{4}{ }^{2-}\right]$, and $\left[\mathrm{HCO}_{3}{ }^{-}\right]$are the concentrations of chloride, sulfate and bicarbonate $(\mathrm{mol} / \mathrm{L})$, respectively.

To evaluate the effect of different disinfectants on iron release, free chlorine was used as disinfectant for L1 and chloramine (monochloramine) was used for L2. For L3 and L4, only $1 \mathrm{mg} / \mathrm{L}$ chloramine was added from day 67 to day 84 (Table 1, Table S3, Table S4). The routine operation cycle procedures were designed to mimic the flow mode in actual distribution system and the household use. Detailed descriptions on the experimental operation for four loops are given in Supporting Information. The water temperature was controlled at $23 \pm 1^{\circ} \mathrm{C}$ using a heat-exchanging unit.

Besides the routine pipe loop operations, long time stagnation was also conducted to examine its effect on iron release and corrosion scale stability.

\subsection{Analytical methods}

Water quality was measured according to Standard Methods (Clesceri et al., 1998). The monitored parameters included $\mathrm{pH}$, conductivity, turbidity, alkalinity, sulfate, chloride, total chlorine, free chlorine, and total iron. The $\mathrm{pH}$ and conductivity were measured using Portable Multiparameter Meter (Sension156 HACH, USA) and the turbidity was measured using a 2100P Turbidimeter (HACH, USA). The total iron was analyzed by the Inductively Coupled Plasma Optical Emission Spectrometer (Perkin-Elmer Optima 2000, USA). The sulfate and chloride were analyzed by Ion Chromatography System-1000 (Dionex, USA). Total chlorine and free chlorine were measured using HACH DR2800 spectrophotometer. Water samples were collected and analyzed at least twice per week; while turbidity and total iron were monitored at least 4 times per week; disinfectant residual was monitored more than 5 times per day sometimes in order to inspect its attenuation process.

\subsection{Physicochemical characterization of iron corrosion scale}

Corrosion scale samples were collected from both the freshly obtained pipe sections and the pipe coupons connected in pipe loop systems. Scale samples were collected twice for L1 
Table 1 - Pipe loop ID, test pipe, historic supply water and respective water treatment plant, feed water and duration of each experimental phase.

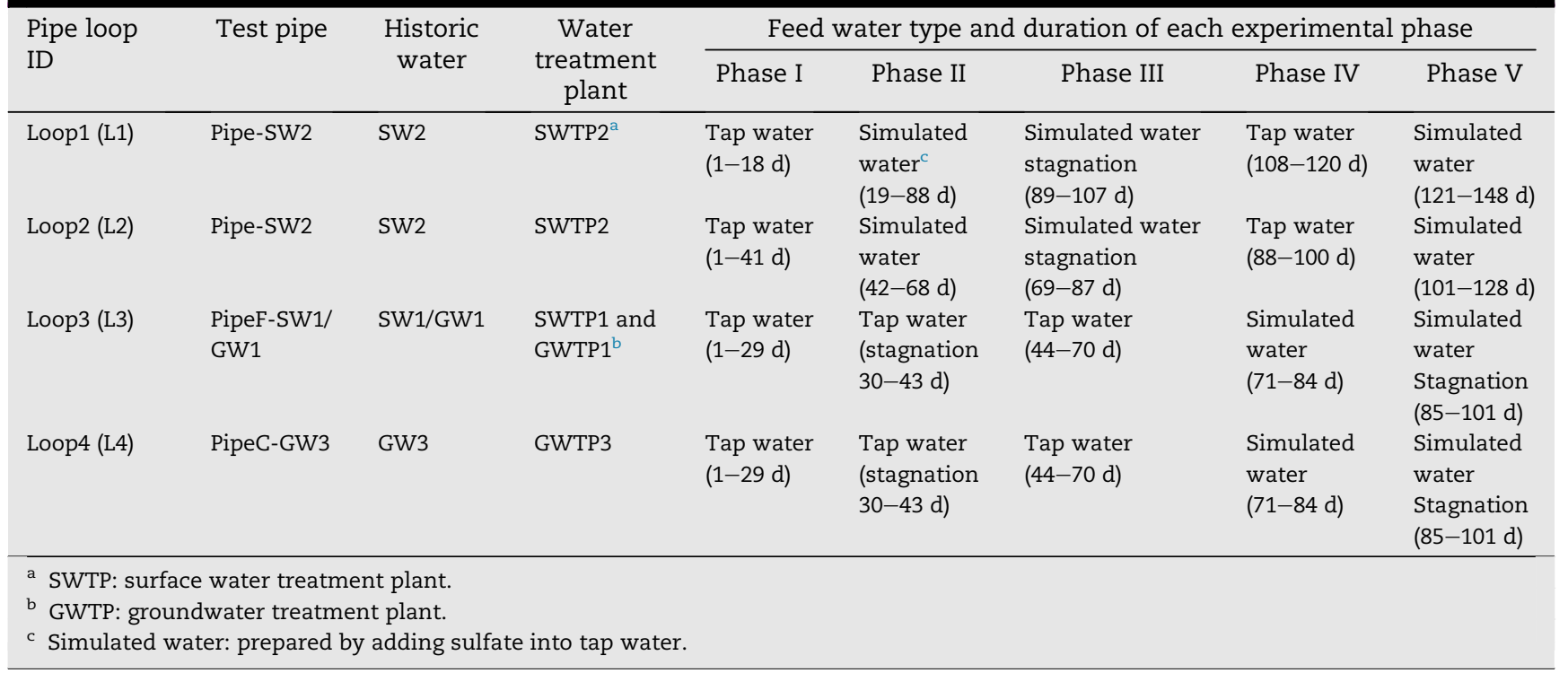

and L2, at the end of phase II and phase III, respectively. For L3 and L4, scale samples were collected 4 times: at the end of phases I and III (under tap water phase), phase IV (under elevated LR water phase), and at the end of phase $\mathrm{V}$ (long stagnation phase). X-ray diffraction (XRD, D/max-rA, Rigaku Co., USA) and X-ray Fluorescence (XRF, Advant' XP, Thermo Electron, Switzerland) were performed to characterize the crystalline phase and elemental composition of corrosion scales. The instrumental information for XRD and XRF as well as the quantification method for XRD were the same as described in a previous study (Yang et al., 2012).

\subsection{DNA extraction}

Total of 30 DNA samples were collected from corrosion scales with different morphologies on collection sites and under different experimental conditions of four pipe loops. DNA was extracted from $0.5 \mathrm{~g}$ fresh scale powder after milled in an anaerobic-glove-box and vacuum-freeze-dried using the FASTDNA SPIN Kit for soil (MP Biomedicals, USA) according to the manufacturer's instructions. The concentration of extracted nucleic acids was determined photometrically using Nanodrop ND-1000 UV-Vis spectrophotometer (Thermo

Table 2 - Main water quality parameters of historic supply water and simulated test water for L1-L4 in each phase.

\begin{tabular}{|c|c|c|c|c|c|c|c|}
\hline \multicolumn{2}{|l|}{ Parameter } & $\mathrm{SO}_{4}{ }^{2-}(\mathrm{mg} / \mathrm{l})$ & $\mathrm{Cl}^{-}(\mathrm{mg} / \mathrm{l})$ & $\mathrm{pH}$ & $\begin{array}{l}\text { Conductivity } \\
(\mu \mathrm{s} / \mathrm{cm})\end{array}$ & $\begin{array}{c}\text { Alkalinity } \\
\left(\mathrm{mg} / \mathrm{L} \mathrm{CaCO}_{3}\right)\end{array}$ & $\mathrm{LR}^{\mathrm{a}}$ \\
\hline \multirow[t]{3}{*}{ Historic supply water } & sw2 & $50.8^{b}$ & 15.8 & 7.84 & 357 & 155.0 & 0.48 \\
\hline & $\begin{array}{l}\text { SW1/ } \\
\text { GW1 }\end{array}$ & 17.1 & 22.7 & 7.43 & 318 & 134.3 & 0.37 \\
\hline & GW3 & 20.1 & 24.4 & 7.16 & 361 & 187.0 & 0.26 \\
\hline \multirow[t]{4}{*}{ Test water for L1 and L2 } & Phase I & 61.8 & 30.2 & 7.60 & 401 & 125.4 & $0.76-0.95^{c}$ \\
\hline & $\begin{array}{l}\text { Phase II } \\
\text { Phase III }\end{array}$ & 298.2 & 82.2 & 7.82 & 912 & 134.0 & $3.25-3.40$ \\
\hline & Phase IV & 52.0 & 37.2 & 7.73 & 366 & 144.3 & $0.69-0.76$ \\
\hline & Phase V & 314.3 & 79.2 & 8.20 & 858 & 132.1 & $3.19-3.55$ \\
\hline \multirow[t]{3}{*}{ Test water for L3 and L4 } & $\begin{array}{l}\text { Phase I } \\
\text { Phase II } \\
\text { Phase III }\end{array}$ & 70.0 & 28.3 & 7.87 & 341 & 127.7 & 0.81 \\
\hline & Phase IV & $\begin{array}{l}116.1(5 d) / 154.9 \\
(5 d) / 346.1(4 d)^{d}\end{array}$ & 18.4 & 7.99 & 743 & 123.6 & $\begin{array}{l}1.16 / 1.40 / \\
3.43^{\mathrm{d}}\end{array}$ \\
\hline & Phase V & 346.1 & 18.4 & 7.99 & 743 & 123.6 & 3.43 \\
\hline 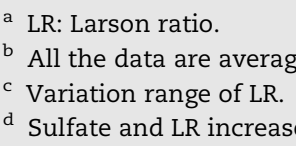 & three of mu & measurements. & & & & & \\
\hline
\end{tabular}



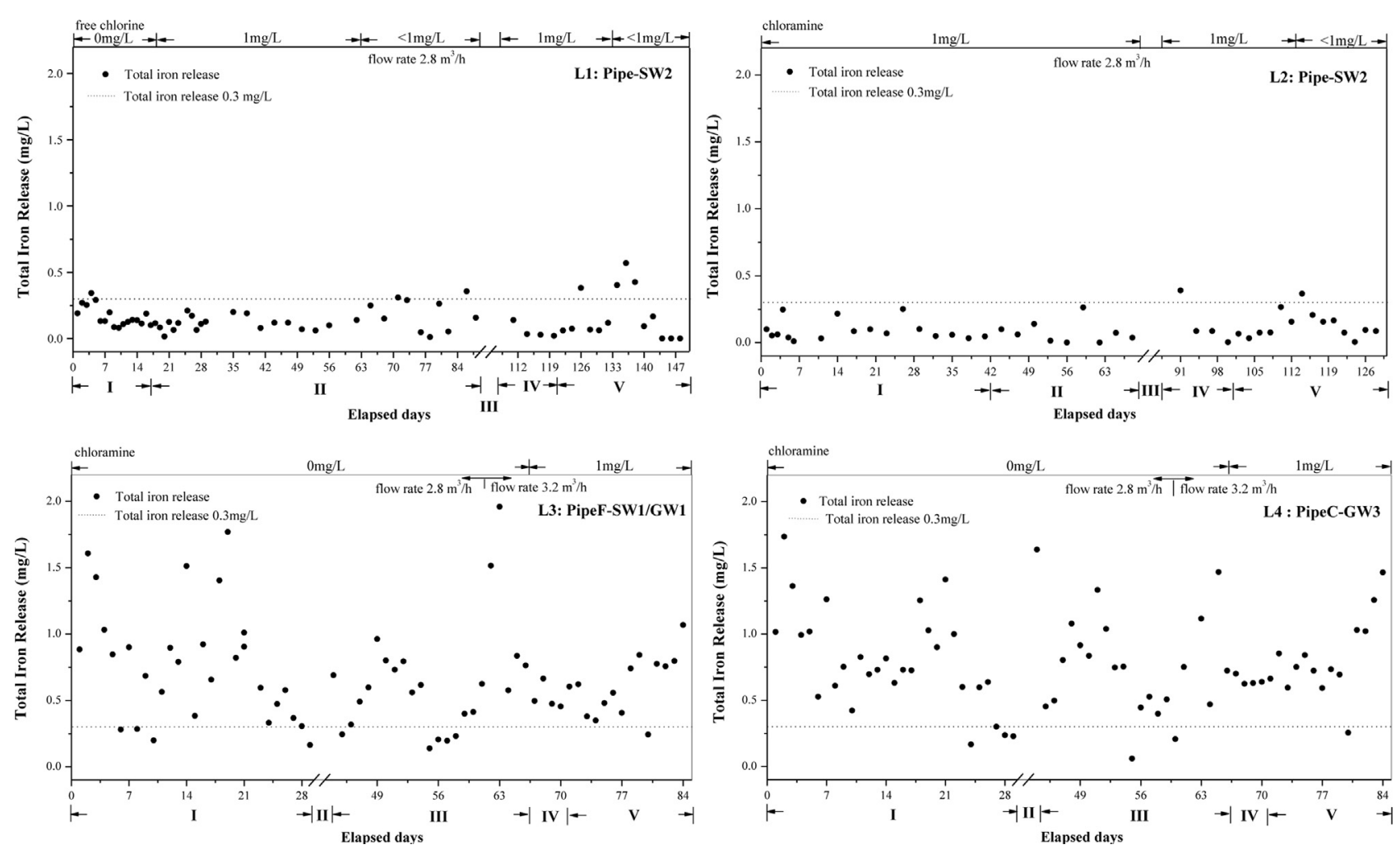

Fig. 2 - Total iron release of L1-L4 under different experimental conditions.

Scientific, USA). All DNA samples were stored at $-20^{\circ} \mathrm{C}$ until further processing.

\subsection{Bacterial community analysis}

The 16S rRNA gene of DNA was amplified by PCR using barcoded primers $8 \mathrm{~F}$ and 533R containing the $\mathrm{A}$ and $\mathrm{B}$ sequencing adaptors (454 Life Sciences, USA) (Bai et al., 2012). The fusion Primer A-8F was $5^{\prime}$-cgtatcgcctccctcgcgccatcagAGAGTTTGATCCTGGCTCAG- $3^{\prime}$, where the sequence of the A adaptor is shown in lowercase letters. The reverse fusion Primer B-533R was $5^{\prime}$-ctatgcgccttgccagccogtcagTTACCGCGGCTGCTGGCAC$3^{\prime}$, where the sequence of the B adaptor is shown in lowercase letters. The ten base pair barcode unique to each sample was embedded in the Primer B-533R set.

The PCR amplification was performed on GeneAmp9700 Thermocycler (ABI, USA). Positive PCR products were purified with AxyPrep DNA Gel Extraction Kit (Axygen, USA). Prior to sequencing, the amplicons from each reaction mixture were mixed in equal amounts based on concentration and subjected to emulsion PCR, and amplicon libraries were generated as recommended by 454 Life Sciences. Sequencing was performed from the primer B end using the 454/Roche B sequencing primer kit using a Roche Genome Sequencer GSFLX according to the protocol.

Pyrosequencing flowgrams were converted to sequence reads using Mothur software (Schloss et al., 2009). Sequence reads were initially filtered and denoized for removing low quality or ambiguous reads (Bai et al., 2012). Then the treated sequences were subjected to systematic checks to remove replicates, duplicates, barcodes, primer sequences and low-quality reads. Briefly, high quality sequences ( $>150 \mathrm{bp}$ in length, quality score $>25$, exact match to barcode and primer, and containing no characters) were remained with an average length of $475 \mathrm{bp}$. Then the remaining high-quality sequences were compared to those in the non-redundant small-subunit (SSU) SILVA111 reference database by kmer searching and the putative chimeric sequences were excluded for further analysis (http://www. arb-silva.de/). Sequences that passed quality control and chimeras' sequences removal were clustered into OTUs using MOTHUR program, with $97 \%$ sequence identity threshold. The species richness estimators (abundancebased coverage estimator [ACE] and Chao1), Shannon diversity index as well as Simpson's diversity index were generated in MOTHUR for each sample. Shannon-Wiener curves were performed on R. Sequences were phylogenetically assigned to taxonomic classifications using an RDP Classifier with a confidence threshold of $80 \%$. After phylogenetic allocation of the sequences down to the phylum, class and genus levels, relative abundance of a given phylogenetic group was set as the number of sequences affiliated with that group divided by the total number of sequences per sample (Lu et al., 2012). Statistical analysis was conducted to reveal the relationship between the bacterial community, samples' environment, scale composition and related methods were given in Supporting Information. 


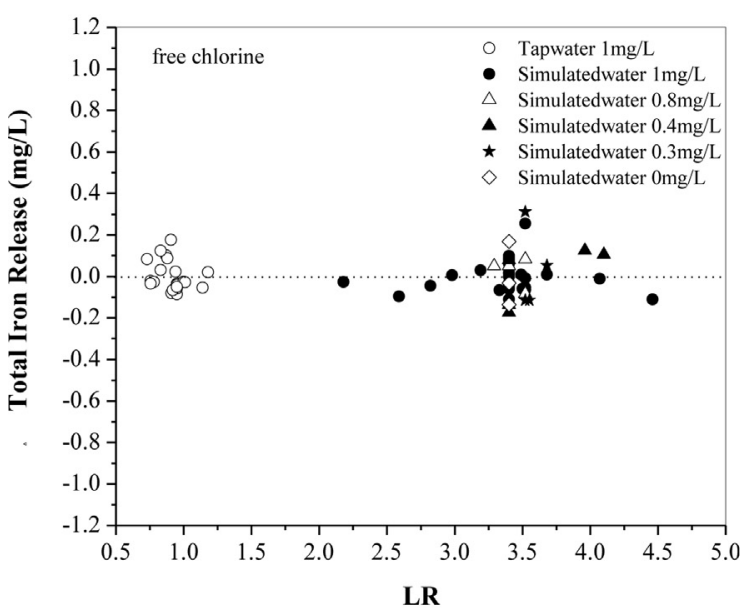

(a)

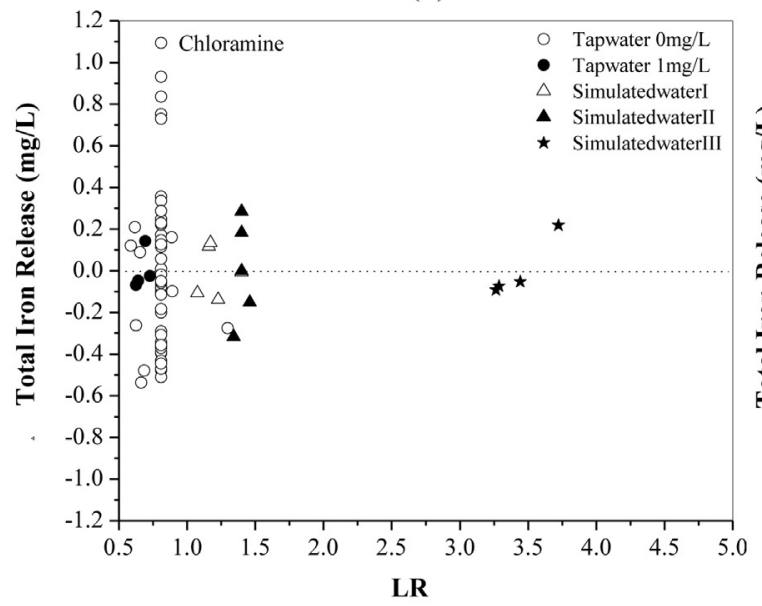

(c)

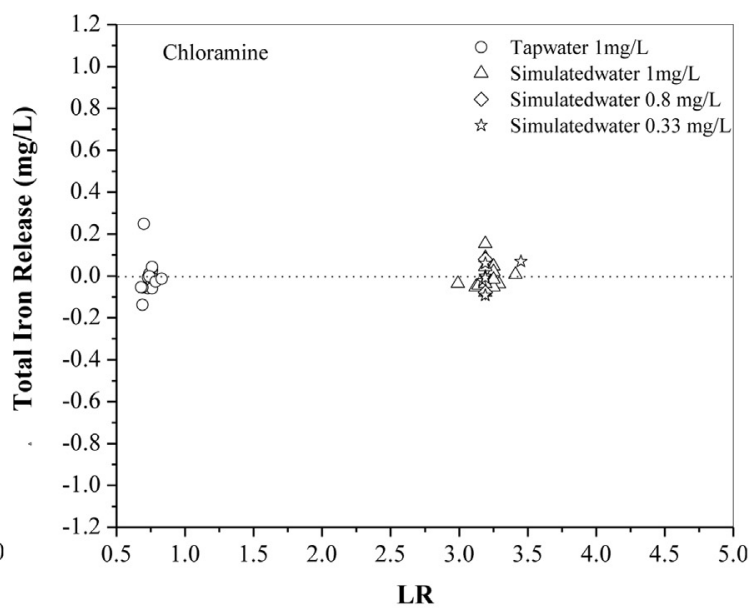

(b)

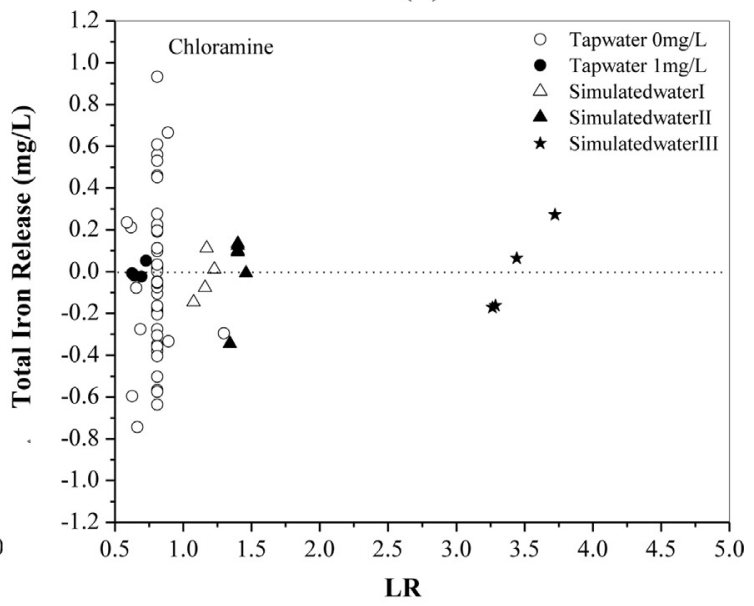

(d)

Fig. 3 - Total iron release fluctuation scenarios for L1 (a), L2 (b), L3 (c) and L4 (d) ( $\Delta$ total iron release = "total iron release of sample measurement" minus "average total iron release in corresponding experimental phase").

\section{Results and discussion}

\subsection{Iron release and turbidity changes}

Fig. 2 shows the total iron release of L1-L4 with elapsed days, and the average values and standard deviations of total iron release and turbidity in different experimental phases are given in Tables S1-S4 for L1-L4, respectively. Before the simulated water was fed into pipe loops, tap water was first introduced to stabilize the newly installed pipe loops since the corrosion scale on pipe surface could be disturbed to some extent during harvest and transportation.

For L1 and L2, the total iron release ranges during the whole experimental phases were $0.01-0.56$ and $0.01-0.39 \mathrm{mg} / \mathrm{L}$, respectively, and almost all the values were below $0.3 \mathrm{mg} / \mathrm{L}$ (the upper limit of drinking water standard for iron in China). When switching to higher LR water or decreasing disinfectant concentration, total iron release increased slightly, then gradually decreased, and finally remained at relatively consistent level (Fig. 2-L1, L2). Long stagnation (phase III) dramatically deteriorated the water quality in pipes (heavy red water with total iron reached 4.30 and $5.84 \mathrm{mg} / \mathrm{L}$ for L1 and L2, respectively), but through routine flow operation, the water quality recovered rapidly in about 4 days (Fig. 2, Table S1, Table S2).

For L3 and L4, total iron release ranges during the whole experimental phases were 0.1-1.9 and 0.05-1.7 mg/L, respectively, and most of the values were above $0.3 \mathrm{mg} / \mathrm{L}$ (Fig. 2-L3, L4). Fig. 2, Table S3 and Table S4 reveal that the iron release and turbidity values for L3 and L4 within phase I, III and IV slightly decreased; moreover, the iron release and turbidity in phase V $(\mathrm{LR}=3.43)$ were increased significantly owning to the substantial LR elevation. Compared with L1 and L2, the effluents of L3 and L4 always exhibited yellowish color under high sulfate water condition, and such phenomenon was consistent with the aforementioned "red water" case in the northern China city.

The total iron release fluctuation scenarios relative to their average values in different experimental phases are illustrated in Fig. 3. The total iron release fluctuation range (" $\Delta$ total iron release" = "total iron release of sample measurement" minus "average total iron release in corresponding experimental phase") under certain operation condition could reflect the pipe scale stability. The " $\Delta$ total iron release" of L3 and L4 under tap water phase was in the range between -0.8 


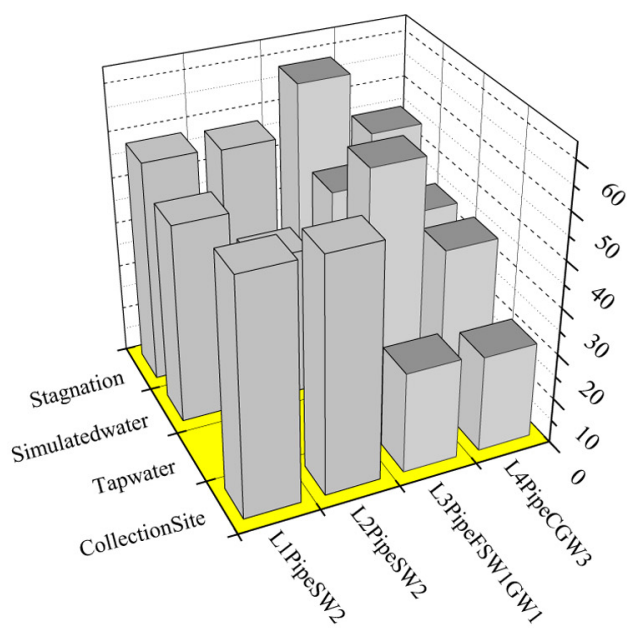

(a)

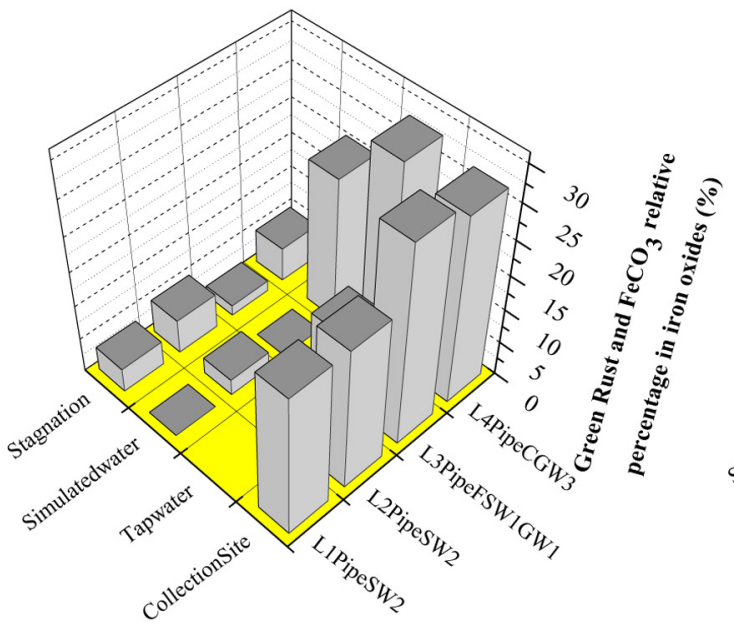

(c)

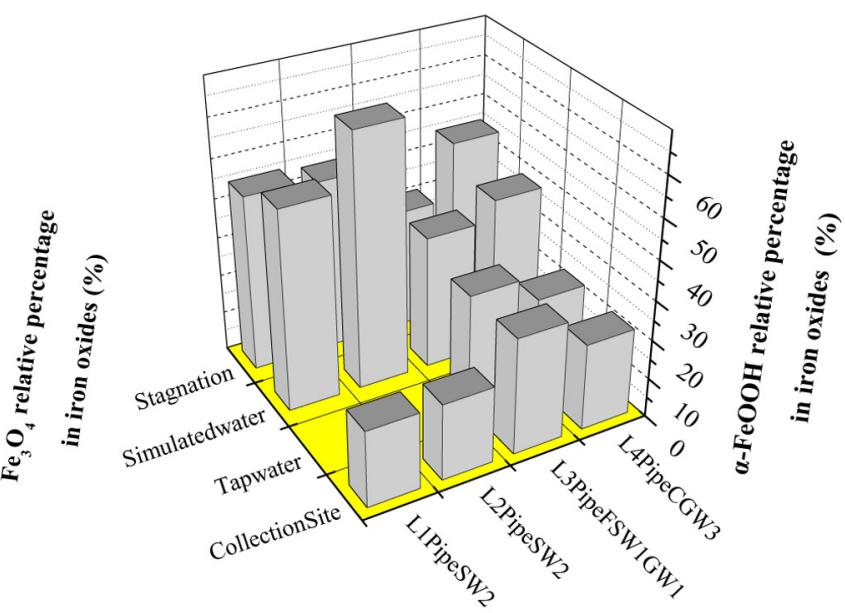

(b)

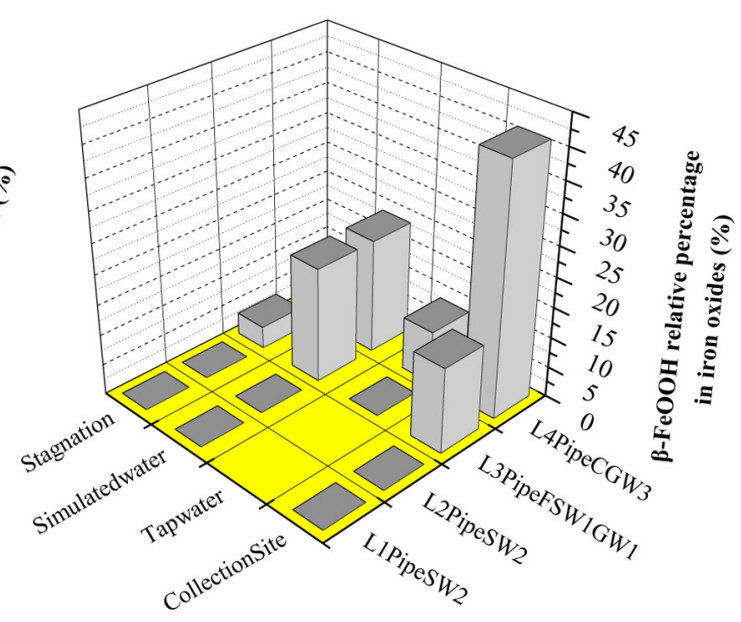

(d)

Fig. 4 - Crystalline composition variation of THS and ET combined samples for pipe loops L1-L4 under different experimental conditions (a) $\mathrm{Fe}_{3} \mathrm{O}_{4}$, (b) $\alpha-\mathrm{FeOOH}$, (c) $\mathrm{GR}$ plus $\mathrm{FeCO}_{3}$, (d) $\beta-\mathrm{FeOOH}$.

and $1.2 \mathrm{mg} / \mathrm{L}$, while the " $\Delta$ total iron release" of L1 and L2 during the whole experimental period was in a much narrower range of between -0.2 and $0.4 \mathrm{mg} / \mathrm{L}$.

All the above results demonstrated that the total iron release behaviors of L1-L2 and L3-L4 are distinctly different under changing sulfate and/or disinfectant conditions. Since the same water matrix (lab tap water) was used and the changed water quality was only sulfate and disinfectant, it could be inferred that the corrosion scale stability of L1-L2 should be much higher than that of L3-L4 (see the following section for corrosion scale comparison and discussion).

\subsection{Scale crystalline composition transformation}

The morphology of corrosion scales was obviously different depending on historic source water types, which had been described in a previous study (Yang et al., 2012). Corrosion scale samples were classified into five types: top surface and hard shell (THS), porous core layer (PCL), entire tubercle without layered structure (ET), thin non-tubercle-formed corrosion scale (TNCS) and hollow tubercle (HT).

Corrosion scale on pipes historically transporting surface water with an appearance of a continuous thick layer $(10-20 \mathrm{~mm})$ can be divided into THS, PCL and ET scale samples for analyses, while the scale on pipes historically transporting groundwater was relatively thin and uniform (only few millimeters or less than a millimeter) with sporadically distributed HT and normal tubercles. The characteristics of corrosion scale on pipes transporting blended surface and groundwater were between the above two kinds of scales.

The 3D plots of some main crystalline iron oxides in THS and ET samples during different experimental phases for all loops (L1-L4) are presented in Fig. 4. The stack bar plots of crystalline composition of TNCS and PCL samples from L3-L4 were also made to compare with THS and ET sample constituent changes (Fig. 5 for TNCS and Fig. S1 for PCL, respectively). All data shown here were the average values of multiple measurements for each pipe section. As the TNCS, THS and ET scales were at the interface between bulk water 


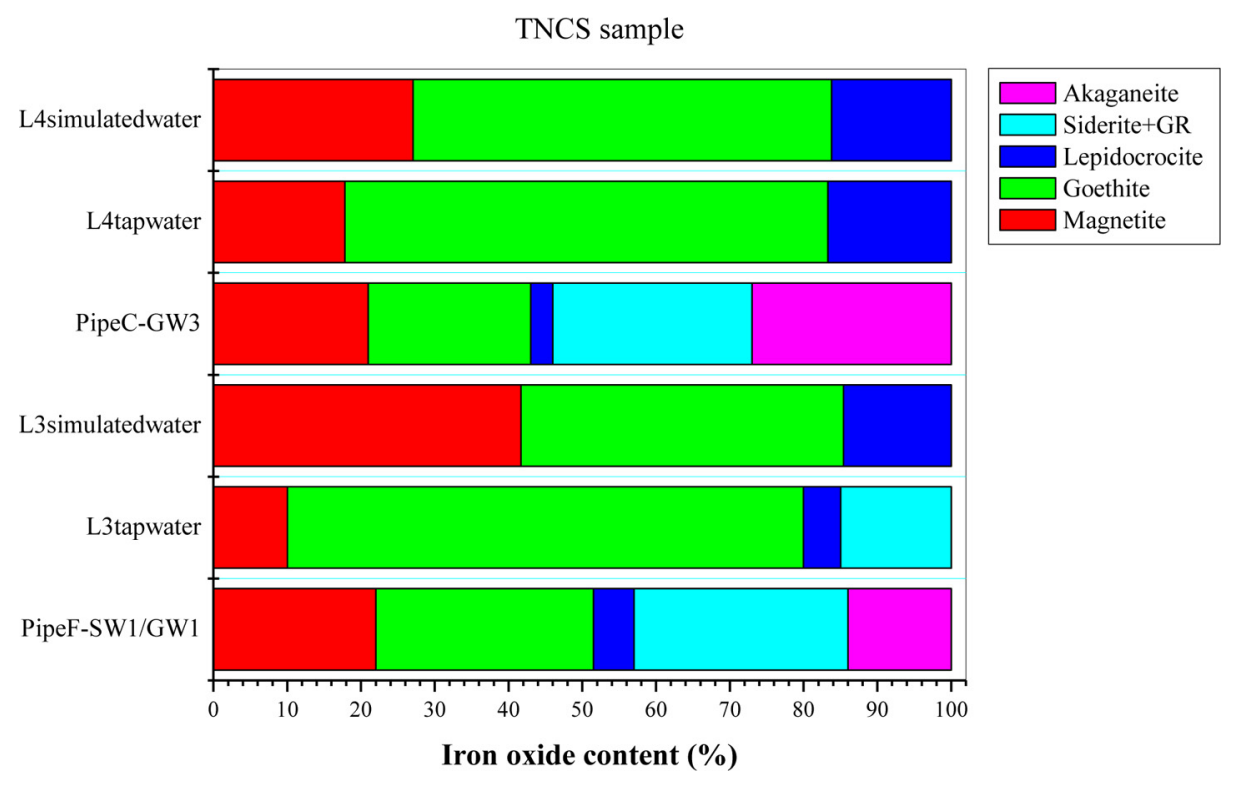

Fig. 5 - Crystalline composition variation of TNCS samples for L3 and L4 under different experimental conditions (Akaganeite: $\beta$-FeOOH; Siderite: $\mathrm{FeCO}_{3}$; GR: Green rust; Lepidocrocite: $\gamma$-FeOOH; Goethite: $\alpha-\mathrm{FeOOH} \mathrm{Magnetite:} \mathrm{Fe}_{3} \mathrm{O}_{4}$ ).

and pipe wall, which served as the barrier of protecting pipe from further corrosion, the structural composition and their stability changes could have great impact on both corrosion and iron release.

For the initial corrosion scale samples (obtained on DWDS sites), $\mathrm{Fe}_{3} \mathrm{O}_{4}$ and/or $\alpha$-FeOOH were found to be the main iron corrosion products. The percentage of $\mathrm{Fe}_{3} \mathrm{O}_{4}$ for Pipe-SW2 scale samples (51\%) was higher than those for PipeF-SW1/ GW1 (22\%) and PipeC-GW3 (21\%). The $\alpha$-FeOOH contents of PipeF-SW1/GW1 scale samples were the highest (30\%). $\mathrm{Fe}_{6}(\mathrm{OH})_{12} \mathrm{CO}_{3} \cdot 2 \mathrm{H}_{2} \mathrm{O}$ (usually called green rust, abbreviated as $\mathrm{GR}$ ) and $\mathrm{Fe}_{2}\left(\mathrm{CO}_{3}\right)(\mathrm{OH})_{2}$ together with $\mathrm{FeCO}_{3}$ (siderite) were detected in corrosion scale samples of all three sites, and their contents were 21\% (Pipe-SW2), 29\% (PipeF-SW1/GW1) and 27\% (PipeC-GW3), respectively. The PipeC-GW3 scale samples had the highest amount of $\beta$-FeOOH (27\%), while Pipe-SW2 scale samples had no $\beta$-FeOOH detected. $\mathrm{Fe}_{3} \mathrm{O}_{4}$ is thermodynamically stable and it could render corrosion scales dense and compact properties, hence, iron corrosion scale with high percentage of $\mathrm{Fe}_{3} \mathrm{O}_{4}$ usually possesses good protective and anti-corrosive properties (Lytle et al., 2005; Sarin et al., 2001, 2004). However, $\beta$-FeOOH, $\mathrm{FeCO}_{3}$ and GR are chemically unstable ferric or ferrous iron oxides. Relatively high percentage of these constituents at the top layer of corrosion scales indicates the weak tolerability of distribution pipes to feed water chemistry changes.

For $\mathrm{L} 3$ and L4, the $\mathrm{Fe}_{3} \mathrm{O}_{4}$ contents in THS and ET corrosion scale samples significantly increased during tap water, simulated water and stagnation phases, whereas for L1 and L2, the $\mathrm{Fe}_{3} \mathrm{O}_{4}$ content under simulated water and stagnation phases changed slightly and maintained dominant constituent (Fig. 4). The different magnetite content changing tendency of L1/L2 and L3/L4 may result from the different morphological and physicochemical characteristics of corrosion scales (more discussion given below). The $\alpha$-FeOOH percentages of THS and ET samples for L1, L2 and L4 all increased from about $20 \%$ to $40-60 \%$. THS and ET samples of L1-L4 all had decreased siderite and GR percentages during the whole experimental phases. The $\beta$-FeOOH content in THS and ET samples of L3 and L4 had a little fluctuation during tap water phase to simulated water phase, but their contents were decreased compared with those of collection site sample. The iron oxides contents changing trends of TNCS on L3 and L4 were almost the same: decreased $\mathrm{Fe}_{3} \mathrm{O}_{4}, \mathrm{FeCO}_{3}, \mathrm{GR}$ and $\beta$ $\mathrm{FeOOH}$ contents, increased $\alpha$-FeOOH contents in tap water phase, and then increased $\mathrm{Fe}_{3} \mathrm{O}_{4}$ and $\alpha$-FeOOH contents, decreased $\mathrm{FeCO}_{3}, \mathrm{GR}$ and $\beta-\mathrm{FeOOH}$ contents in simulated water phase (Fig. 5). It was reported that GRs can be oxidized by dissolved $\mathrm{O}_{2}$ into $\mathrm{Fe}_{3} \mathrm{O}_{4}, \alpha-\mathrm{FeOOH}, \gamma$-FeOOH or $\gamma-\mathrm{Fe}_{2} \mathrm{O}_{3}$ depending on $\mathrm{pH}$ and oxidation rate (Erbs, 2004; Pineau et al., 2008). Under the condition of this investigation, the dissolved $\mathrm{O}_{2}$ concentration in the pipe loops was considered relatively higher than that in actual DWDS condition because oxygen could continuously dissolved into the experimental loops through the feed water tank. GR might be mainly transformed into $\mathrm{Fe}_{3} \mathrm{O}_{4}$ and $\alpha$-FeOOH since these two constituents increased with the decrease of GR.

The PCL composition changing trends of L1 and L2 samples were basically the same as those of THS and ET samples (Fig. S1). However, the scale composition changing trends of PCL samples on L3 and L4 were different with those of their THS and ET samples.

The stable constituent (mainly $\mathrm{Fe}_{3} \mathrm{O}_{4}$ ) of THS, ET and PCL samples of L1 and L2 both changed less, while siderite and GR (as corrosion intermediate products) of those samples decreased markedly. Lower level total iron release of L1 and L2 under high sulfate water could be attributed to their specific corrosion scale characteristics: thick protective scales with higher percentage of chemically stable corrosion products (mainly $\mathrm{Fe}_{3} \mathrm{O}_{4}$ ). On the other hand, the higher total iron release of L3 and L4 during feed water switch mainly resulted from their thin layer with lower percentage of $\mathrm{Fe}_{3} \mathrm{O}_{4}$ and higher 

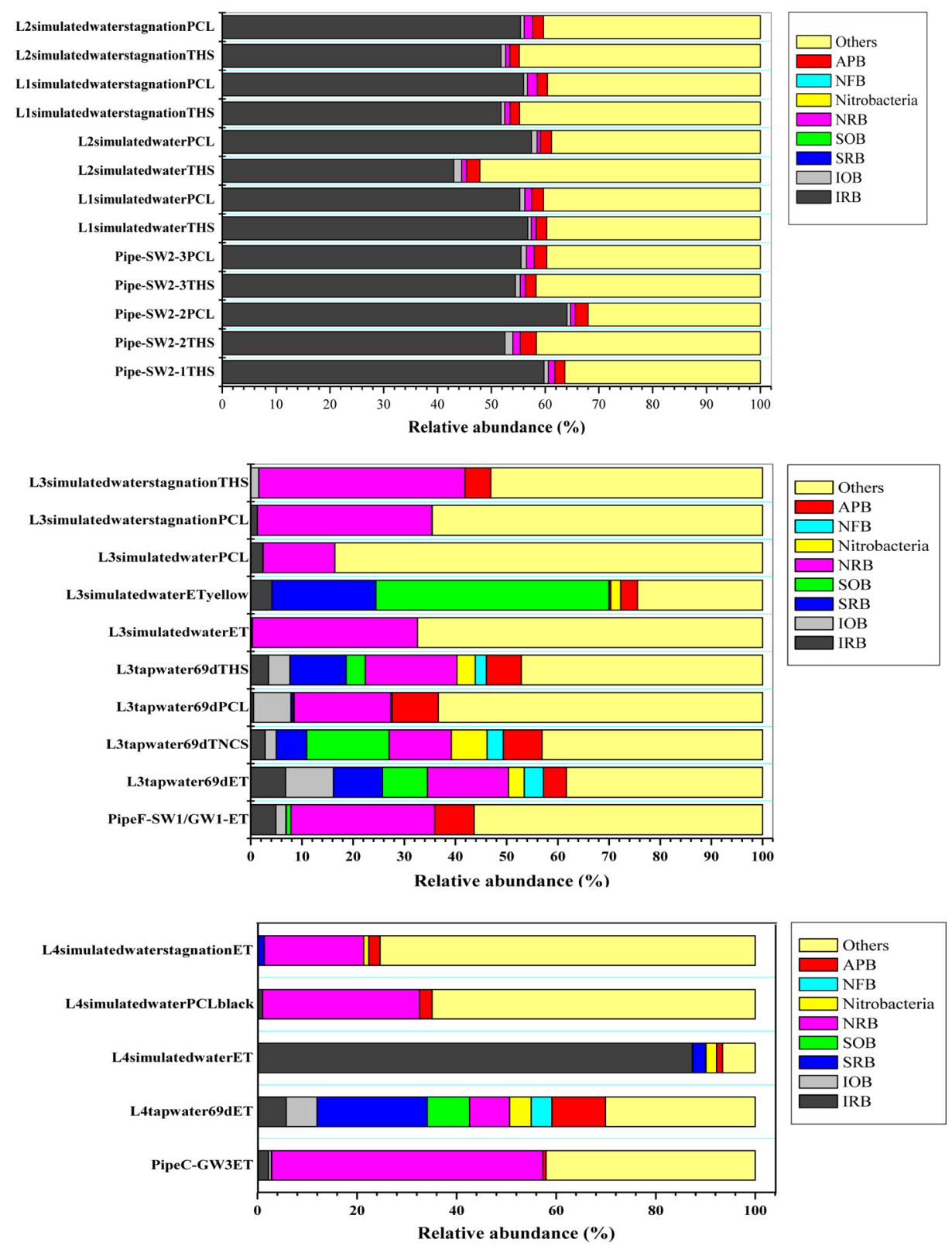

Fig. 6 - Variation of bacterial community on corrosion scales of L1-L4 under different experimental conditions.

percentages of unstable iron oxides ( $\beta-\mathrm{FeOOH}, \mathrm{FeCO}_{3}$ and $\left.\mathrm{GR}\right)$. In addition, the lower $\mathrm{Fe}_{3} \mathrm{O}_{4}$ content, higher $\beta$-FeOOH content on L3 PCL samples, as well as the higher $\mathrm{FeCO}_{3}$ and GR in L4 PCL samples under tap water and simulated water phases could account for the relatively higher iron release of L3 and L4 (Fig. S1).

However, under elevated sulfate experimental phases, $\mathrm{Fe}_{3} \mathrm{O}_{4}$ content of THS, ET and TNCS samples from L3 and L4 had increasing trend, while $\mathrm{FeCO}_{3}$ and $\mathrm{GR}, \beta$-FeOOH (unstable iron oxide) contents of those samples were decreasing. Therefore, it can be inferred that the pipe scales of L3 and L4 gradually become more stable. The phenomenon that total iron release of L3 and L4 had slight decrease with time evidenced the above ratiocination (Fig. 2, Table S3 and Table S4).

\subsection{Transformation of corrosion related bacterial communities}

In order to understand the possible roles of bacteria in the corrosion scale transformation and iron release, the bacterial community in scale samples including those collected on DWDS sites and under different experimental conditions for all pipe loops were determined by $16 \mathrm{~S}$ rRNA pyrosequencing and the statistical results are presented in Fig. 6.

According to the possible functions of bacteria genera, the bacterial community were classified into IOB (iron oxidizing bacteria), IRB (iron reducing bacteria), SOB (sulfur oxidizing bacteria), SRB (sulfate reducing bacteria), NRB (nitrate reducing bacteria), APB (acid producing bacteria), nitrobacteria and NFB (nitrogen fixing bacteria) (Emde et al., 1992; 
Weber et al., 2006). The anterior six groups were frequently observed in corrosion phenomena (shown in Table S5). Based on the taxonomic analysis of 16S rRNA gene sequences, 30 most abundant genera in each sample were identified and classified into the above eight functional groups, as shown in Fig. 6. For L1 and L2, the bacterial communities of Pipe-SW2 scales from collection site, samples collected under high LR and stagnation were rather similar, with IRB being the dominant community (43.0-64.1\%), which included Bacillus, Clostridium, Escherichia, Pseudomonas and Shewanella. The iron reducing function of these genera had been reported by many researchers (Emde et al., 1992; Weber et al., 2006; Herrera and Videla, 2009). The minor communities of original Pipe-SW2 scales and its corresponding L1 and L2 scale samples included IOB, NRB and APB, meanwhile, small fraction $(<0.1 \%)$ of SOB (Alicyclobacillus, Sulfuricella, Sulfuricurvum, Sulfurospirillum and Thiobacillus) and SRB (Desulfosporosinus, Desulfovibrio and Desulfurivibrio) were observed in the above scale samples.

There are conflicting reports in the literature concerning the effect of IRB on iron corrosion. IRB were considered to promote corrosion either by reductively dissolving the protective ferric oxides or by enhancing corrosion itself (Iwona and Christine, 1999). Nevertheless, recent studies indicated that IRB could play corrosion inhibition roles by forming a protective biofilm or reducing dissolved $\mathrm{O}_{2}$ diffusion (Dubiel et al., 2002; Herrera and Videla, 2009; Wang et al., 2012).

NRB (Delftia and Ochrobactrum) were the relatively higher abundance group (28.1\%) in scale samples collected on PipeF-SW1/GW1. After contacting with tap water for 69 days, the IRB in THS, ET, TNCS and PCL scale samples corresponding to L3 (PipeFSW1/GW1) were only a minor (0.5-6.8\%) community. Meanwhile the amount of IOB (Acidovorax, Alicyclobacillus, and Gallionella), SOB (Sulfuricella and Thiobacillus) and SRB (Desulfovibrio and Desulfosporosinus) in those scales had increased to different extents, which could attributed to the elevated sulfate concentration of tap water compared with historical groundwater. After $14 \mathrm{~d}$ of much higher sulfate period, the ET and PCL scale contained a larger fraction of NRB (32.3\% and $14.0 \%)$, while the yellow ET scale harbored a high fraction of SOB (45.5\%) and SRB (20.3\%). After 35 d stagnation, the THS and PCL scale had a higher fraction of NRB ( $40.3 \%$ and $34.1 \%)$. It is well known that SRB are the most principal microorganism which induces iron corrosion/degradation (Emde et al., 1992; Iwona and Christine, 1999). Nitrification may also promote corrosion, as this process results in $\mathrm{pH}$ dropping, which increases the solubility of most metal minerals commonly found in corrosion scale (White et al., 2011).

Similar with site collection scale samples of PipeF-SW1/ GW1, the original ET scale of PipeC-GW3 had the main groups of NRB (54.5\%). After introducing tap water for 69d, the ET scale in L4 had a slightly increased fraction of IRB (from $2.2 \%$ to $5.8 \%$ ), IOB (from $0.6 \%$ to $6.2 \%$ ), SOB (from $0.02 \%$ to $8.5 \%$ ), SRB (from $0.05 \%$ to $22.1 \%$ ), APB (from $0.7 \%$ to $10.8 \%$ ) and greatly decreased fraction of NRB (from $54.5 \%$ to $8.0 \%$ ). ET sample of L4 under $14 \mathrm{~d}$ high sulfate condition harbored a much higher fraction of IRB (87.4\%) and a decreased fraction of IOB, SRB, SOB, APB and NRB. While the black PCL scale of L4 contained a lower fraction of IRB, APB and a high fraction of
NRB. After 35 d stagnation, SRB (1.4\%), NRB (20.0\%) and APB (2.3\%) became the main groups in L4 ET scale.

In general, the upon-collection site scale samples of pipe historically transporting surface water contained a high fraction of IRB ( $>40 \%)$, medium fractions of IOB, NRB and APB $(<10 \%)$, and a low fraction of SOB and SRB $(<0.1 \%)$. Though the $\alpha-\mathrm{FeOOH}, \mathrm{FeCO}_{3}$ and GR contents in $\mathrm{L} 1$ and $\mathrm{L} 2$ scales had great alteration under high sulfate water, the bacterial community did not changed greatly. However, the upon-collection site scale samples of pipe historically transporting blends or groundwater contained high fraction of NRB (>20\%), medium fraction of IRB, APB $(<10 \%)$ and a low fraction of SOB and SRB $(<1 \%)$. But the relative abundances of IOB, SOB, SRB, NRB and APB in TNCS, PCL, THS or ET scales of L3 and L4 increased to some extent at $69 \mathrm{~d}$ tap water period. As the pipes of L3 and L4 did not have thick, dense and protective corrosion scales, high sulfate ions in simulated water caused high iron release and corrosion, which was in accordance with the increase of certain bacterial communities that promote corrosion. As to the pipes of L1 and L2, with the relatively stable corrosion scales and the much lower iron release, the bacterial community, particularly IRB changed slightly.

\subsection{Interrelationships of sulfate, scale composition, bacteria community and iron release}

The interrelationships of sulfate, bacterial community and corrosion scale composition were statistically analyzed (analytical methods were given in Supporting Information). The redundancy analysis (RDA) results on L1 and L2 demonstrated that $\mathrm{SO}_{4}{ }^{2-}$ had positive correlation with $\alpha$-FeOOH content (Fig. S2-a); meanwhile, canonical correspondence analysis (CCA) results of $\mathrm{L} 3$ and $\mathrm{L} 4$ showed that $\mathrm{SO}_{4}{ }^{2-}$ had positive relationship with $\mathrm{Fe}_{3} \mathrm{O}_{4}$ (Fig. S2-b, c). The cosine values of the angle between the arrow lines of $\mathrm{Fe}_{3} \mathrm{O}_{4}$ and two bacterial genera (Escherichia-Shigella and Pseudomonas) indicated that the two genera had positive relationship with $\mathrm{Fe}_{3} \mathrm{O}_{4}$ for L1 and L2 (Fig. S2-a). Additionally, IOB, SOB, SRB and APB had positive relationship with $\mathrm{Fe}_{3} \mathrm{O}_{4}$ and $\alpha$-FeOOH for L3 and L4 (Fig. S2-b. c).

All these relationships were consistent with the observations shown in Figs. 4 and 5. The IRB relative abundance and $\mathrm{Fe}_{3} \mathrm{O}_{4}$ content of $\mathrm{L} 1$ and $\mathrm{L} 2$ samples changed little under different experimental phases. The increased abundances of IOB, SOB, SRB and APB in L3 and L4 samples under tap water and simulated water period were in accordance with the increased amount of $\alpha$-FeOOH.

It could be deduced that the maintenance of large proportion $\mathrm{Fe}_{3} \mathrm{O}_{4}$ and IRB for Pipe-SW2 scales within a wide range of sulfate concentration could attributed to the existence of rather thick corrosion scales and the dense-compact layer, which served as barrier hindering the diffusion of dissolved oxygen and corrosive ions into the metallic surface. Additionally, the high abundance of IRB in scales was in favor of the formation and preservation of $\mathrm{Fe}_{3} \mathrm{O}_{4}$. Thus, the morphological, physicochemical characteristics of corrosion scales and the bacterial community of L1 and L2 could account for the much lower iron release under high sulfate water condition.

Bacterial community in L3 and L4 also played crucial roles in scale chemical transformation as well as the higher level 
total iron release under high sulfate water condition. As shown in Fig. S2, deceased $\mathrm{Fe}_{3} \mathrm{O}_{4}$ content of TNCS under tap water phase, decreased $\mathrm{FeCO}_{3}, \mathrm{GR}$ and $\beta$-FeOOH contents of THS, ET and TNCS under tap water and simulated water phases were all correlated with certain bacteria genera. Chemically unstable $\mathrm{Fe}(\mathrm{III})$ oxides (e.g. $\beta$-FeOOH) might be reduced by IRB to transform into GR (Erbs, 2004), $\mathrm{Fe}_{3} \mathrm{O}_{4}$ and $\mathrm{FeCO}_{3}$ (Lee et al., 2003; Kukkadapu et al., 2005) or reduced by hydrogen sulfide produced by SRB to form $\mathrm{S}^{0}$ and Fe(II) oxides. The higher solubility of Fe(II) oxides led to more iron released into bulk water and consequently caused the formation of red water (Lytle et al., 2005). In addition, SRB proliferation favored sulfide production and hindered the formation of $\mathrm{Fe}_{3} \mathrm{O}_{4}$, thus promoted iron corrosion and iron release (Lytle et al., 2005; Pineau et al., 2008). The presence of SRB is often characterized by the presence of $\mathrm{S}^{0}$ and $\mathrm{Fe}_{\mathrm{x}} \mathrm{S}_{\mathrm{y}}$ minerals, e.g. FeS, $\mathrm{FeS}_{2}$, $\mathrm{Fe}_{3} \mathrm{~S}_{4}$, or amorphous iron sulfide ( $\mathrm{FeS}_{\text {amorph }}$ ) (Lytle et al., 2005). Crystalline $\mathrm{Fe}_{\mathrm{x}} \mathrm{S}_{\mathrm{y}}$ minerals were not detected by XRD in this study, but XRF results demonstrated that $S^{0}$ was commonly existed and Sx (sulfide sulfur) was also observed (Table S6). Eqs. (2) and (3) are the possible transformation reactions for $S^{0}$, sulfate and hydrogen sulfide. The existence of hydrogen sulfide was partially confirmed by its characteristic rotten egg smell (Lytle et al., 2005).

$2 \mathrm{FeOOH}+\mathrm{H}_{2} \mathrm{~S}+4 \mathrm{H}^{+} \rightarrow 2 \mathrm{Fe}^{2+}+\mathrm{S}^{0}+4 \mathrm{H}_{2} \mathrm{O}$

$4 \mathrm{FeOOH}+1 / 2 \mathrm{H}_{2} \mathrm{~S}+7 \mathrm{H}^{+} \rightarrow 4 \mathrm{Fe}^{2+}+1 / 2 \mathrm{SO}_{4}{ }^{2-}+6 \mathrm{H}_{2} \mathrm{O}$

As aforementioned, $\mathrm{Fe}_{3} \mathrm{O}_{4}$ has been recognized as a major constituent in protective iron corrosion scales, but SRB hinders its formation. Nevertheless, L3 and L4 scales had increased $\mathrm{Fe}_{3} \mathrm{O}_{4}$ for THS and ET combined samples (Fig. 4) after switching to tap water and for TNCS samples after switching to simulated water (Fig. 5). This phenomenon might be the combined effect of all bacterial communities, including IOB, IRB and SOB. Some recent research had found that the SOB and IRB could inhibit the SRB-induced corrosion (Duan et al., 2008; Lee et al., 2006; Pineau et al., 2008). Bacteria associated with iron pipe corrosion (SOB, SRB, IOB, IRB etc.) are often observed coexisting in biofilms and they could exhibit synergistic or inhibitive effect on corrosion processes (Iwona and Christine, 1999; Pineau et al., 2008).

\section{Conclusions}

Understanding the transformation characteristics of iron corrosion scale and concomitant bacterial community in DWDS under the condition of changing water supply condition is crucial for safe drinking water transportation from treatment plants to consumer taps. The main conclusions of this investigation include:

The pipes historically transporting treated surface water had more stable corrosion scales and only slight increase of iron release occurred when changing to water with multiply higher sulfate; the pipes historically transporting treated groundwater or blends had more severe iron release when feed water sulfate concentration increased.
For the pipes with stable corrosion scales, long-stagnation and decreased disinfectant concentration temporarily deteriorated water quality, which could be recovered quickly after normal operation was resumed.

The corrosion scales of pipes used to transporting treated surface water could maintain its relatively larger proportion of stable constituents (mainly $\mathrm{Fe}_{3} \mathrm{O}_{4}$ ) when feed water switched to much higher sulfate water; while the corrosion scales of pipes used to transporting treated groundwater or blends changed more markedly from less stable to more stable constituents when feed water switched to higher sulfate water.

The main functional bacterial community and its relative abundance (a high fraction of IRB, 43-65\%) in corrosion scales of pipes historically transporting treated surface water did not have drastic variation under feed water changing condition. But IRB abundance in scales of pipes transporting treated groundwater or blends were below $5 \%$ and elevated sulfate triggered significant increase of SOB, SRB and IOB, which could enhance iron corrosion and promote corrosion product release.

\section{Acknowledgments}

This work was financially supported by National Natural Science Foundation of China (51178450, 51378493 and 51308392) and National Water Pollution Control and Treatment Special Key Project of China (2012ZX07404-002, 2012ZX07408-002).

\section{Appendix A. Supplementary data}

Supplementary data related to this article can be found at http://dx.doi.org/10.1016/j.watres.2014.04.003.

\section{R E F E R E N C E S}

Bai, Y.H., Shi, Q., Wen, D.H., Li, Z.X., Jefferson, W.A., Feng, C.P., et al., 2012. Bacterial cmmunities in the sdiments of Dianchi lke, a prtitioned etrophic waterbody in China. Plos One 7 , e37796.

Clesceri, L.S., Greenberg, A.E., Eaton, A.D., 1998. Standard Method for the examination of water and wastewater, 20th ed. American Public Health Association, Washington.

Duan, J.Z., Wu, S.R., Zhang, X.J., Huang, G.Q., Du, M., Hou, B.R., 2008. Corrosion of carbon steel influenced by anaerobic biofilm in natural seawater. Electrochim. Acta 54, 22-28.

Dubiel, C.H., Hsu, C.C., Chien, F.M., Newman, D.K., 2002. Microbial iron respiration can protect steel from corrosion. Appl. Environ. Microbiol. 68 (3), 1440-1445.

Emde, K.M.E., Smith, D.W., Facey, R., 1992. Initial investigation of microbially influenced corrosion (MIC) in a low temperature water distribution system. Water Res. 26 (2), 69-175.

Erbs, M., 2004. Formation and Redox Reactions of Green Rusts under Geochemical Conditions Found in Natural Soils and Sediments. Doctor Dissertation. Swiss Federal Institute of Technology.

Herrera, L.K., Videla, H.A., 2009. Role of iron-reducing bacteria in corrosion and protection of carbon steel. Int. Biodeterior. Biodegrad. 63, 891-895. 
Imran, S.A., Dietz, J.D., Mutoti, G., 2006. Optimizing source water blends for corrosion and residual control in distribution systems. J. Am. Water Works Assoc. 98 (5), 101-115.

Iwona, B.B., Christine, C.G., 1999. Recent advances in the study of biocorrosion-an overview. Rev. Microbiol. 30 (3), 177-190.

Kukkadapu, R.K., Zachara, J.M., Fredrickson, J.K., Kennedy, D.W., Dohnalkova, A.C., Mccready, D.E., 2005. Ferrous hydroxyl carbonate is a stable transformation product of biogenic magnetite. Am. Mineral. 90, 510-515.

Lee, S.H., Lee, I., Roh, Y., 2003. Biomineralization of a poorly crystalline Fe(III) oxide, akaganeite, by an anaerobic Fe(III)reducing bacterium (Shewanella alga) isolated from marine environment. Geosci. J. 7 (3), 217-226.

Lee, A.K., Buehler, M.G., Newman, D.K., 2006. Influence of dual species biofilm on the corrosion of mild steel. Corros. Sci. 48, 165-178.

Li, D., Li, Z., Yu, J.W., Cao, N., Liu, R.Y., Yang, M., 2010. Characterization of bacterial community structure in a DWDS during an occurrence of red water. Appl. Environ. Microbiol. 76 (21), 7171-7180.

Lu, L., Xing, D.F., Ren, N.Q., 2012. Pyrosequencing reveals highly diverse microbial communities in microbial electrolysis cells involved in enhanced $\mathrm{H}_{2}$ production from waste activated sludge. Water Res. 46, 2425-2434.

Lytle, D.A., Gerke, T.L., Maynard, J.B., 2005. Effect of bacterial sulfate reduction on iron-corrosion scales. J. Am. Water Works Assoc. 97 (10), 572-579.

Niquette, P., Servais, P., Savoir, R., 2001. Bacterial dynamics in the DWDS of Brussels. Water Res. 35, 675-682.

Park, H.S., Chatterjee, I., Dong, X.L., Wang, S.H., Sensen, C.W., Caffrey, S.M., Jack, T.R., Boivin, J., Voordouw, G., 2011. Effect of sodium bisulfite injection on the microbial community composition in a brackish-water-transporting pipeline. Appl. Environ. Microbiol. 77 (19), 6908-6917.

Pavissich, J.P., Vargas, I.T., González, B., Pastén, P.A., Pizarro, G.E., 2010. Culture dependent and independent analyses of bacterial communities involved in copper plumbing corrosion. J. Appl. Microbiol. 109 (3), 771-782.
Pineau, S., Sabot, R., Quillet, L., Jeannin, M., Caplat, Ch, DupontMorral, I., Refait, Ph, 2008. Formation of the Fe(II-III) hydroxysulphate green rust during marine corrosion of steel associated to molecular detection of dissimilatory sulphitereductase. Corros. Sci. 50, 1099-1111.

Sarin, P., Snoeyink, V.L., Bebee, J., 2001. Physico-chemical characteristics of corrosion scales in old iron pipes. Water Res. 35 (12), 2961-2969.

Sarin, P., Snoeyink, V.L., Lytle, D.A., 2004. Iron corrosion scales: model for scale growth, iron release and colored water formation. J. Environ. Eng. 130 (4), 364-373.

Schloss, P.D., Westcott, S.L., Ryabin, T., Hall, J.R., Hartmann, M., 2009. Introducing mothur: open-source, platform-

Independent, community-supported software for describing and comparing microbial communities. Appl. Environ. Microbiol. 75, 7537-7541.

Tang, Z.J., Hong, S.K., Xiao, W.Z., 2006. Characteristics of iron corrosion scales established under blending of ground, surface, and saline waters and their impacts on iron release in the pipe distribution system. Corros. Sci. 48 (2), 322-342.

Teng, F., Guan, Y.T., Zhu, W.P., 2008. Effect of biofilm on cast iron pipe corrosion in DWDS: corrosion scales characterization and microbial community structure investigation. Corros. Sci. 50 (10), 2816-2823.

Wang, H., Hu, C., Hu, X., Yang, M., Qu, J., 2012. Effects of disinfectant and biofilm on the corrosion of cast iron pipes in a reclaimed water distribution system. Water Res. 46 (4), 1070-1078.

Weber, K.A., Achenbach, L.A., Coates, J.D., 2006. Microorganisms pumping iron: anaerobic microbial iron oxidation and reduction. Nat. Rev. 4, 752-764.

White, C., Tancos, M., Lytle, D.A., 2011. Microbial community profile of a lead service line removed from a DWDS. Appl. Environ. Microbiol. 77 (15), 5557-5561.

Yang, F., Shi, B., Gu, J., Wang, D., Yang, M., 2012. Morphology and composition characteristics of iron corrosion scales formed under different water source histories in a drinking water distribution system. Water Res. 46, 5423-5433. 